\title{
Article \\ Carbon-Encapsulated Iron Nanoparticles as a Magnetic Modifier of Bioanode and Biocathode in a Biofuel Cell and Biobattery
}

\author{
Roman Chomicz, Michał Bystrzejewski and Krzysztof Stolarczyk *
}

check for

updates

Citation: Chomicz, R.;

Bystrzejewski, M.; Stolarczyk, K.

Carbon-Encapsulated Iron

Nanoparticles as a Magnetic

Modifier of Bioanode and

Biocathode in a Biofuel Cell and

Biobattery. Catalysts 2021, 11, 705.

https://doi.org/

10.3390/catal11060705

Academic Editor: Barbara Mecheri

Received: 9 May 2021

Accepted: 31 May 2021

Published: 2 June 2021

Publisher's Note: MDPI stays neutral with regard to jurisdictional claims in published maps and institutional affiliations.

Copyright: (C) 2021 by the authors. Licensee MDPI, Basel, Switzerland. This article is an open access article distributed under the terms and conditions of the Creative Commons Attribution (CC BY) license (https:// creativecommons.org/licenses/by/ $4.0 /)$.
Faculty of Chemistry, University of Warsaw, Pasteura 1, 02-093 Warsaw, Poland; ceremonys.roman@gmail.com (R.C.); mibys@chem.uw.edu.pl (M.B.)

* Correspondence: kstolar@chem.uw.edu.pl; Tel.: +48-228-226-351

\begin{abstract}
This work demonstrates the application of magnetic carbon-encapsulated iron nanoparticles (CEINs) for the construction of bioelectrodes in a biobattery and a biofuel cell. It has been shown that carbon-encapsulated iron nanoparticles are a suitable material for the immobilization of laccase (Lc) and 1,4-naphthoquinone (NQ) and fructose dehydrogenase (FDH). The system is stable; no leaching of the enzyme and mediator from the surface of the modified electrode was observed. The onset of the catalytic reduction of oxygen to water was at $0.55 \mathrm{~V}$, and catalytic fructose oxidation started at $-0.15 \mathrm{~V}$. A biobattery was developed in which a zinc plate served as the anode, and the cathode was a glassy carbon electrode modified with carbon-encapsulated iron nanoparticles, laccase in the Nafion (Nf) layer. The maximum power of the cell was ca. $7 \mathrm{~mW} / \mathrm{cm}^{2}$ at $0.71 \mathrm{~V}$ and under external resistance of $1 \mathrm{k} \Omega$. The open-circuit voltage $(\mathrm{OCV})$ for this system was $1.51 \mathrm{~V}$. In the biofuel cell, magnetic nanoparticles were used both on the bioanode and biocathode to immobilize the enzymes. The glassy carbon bioanode was coated with carbon-encapsulated iron nanoparticles, 1,4-naphthoquinone, fructose dehydrogenase, and Nafion. The cathode was modified with carbonencapsulated magnetic nanoparticles and laccase in the Nafion layer. The biofuel cell parameters were as follows: maximum power of $78 \mu \mathrm{W} / \mathrm{cm}^{2}$ at the voltage of $0.33 \mathrm{~V}$ and under $20 \mathrm{k} \Omega$ resistance, and the open-circuit voltage was $0.49 \mathrm{~V}$. These enzymes worked effectively in the biofuel cell, and laccase also effectively worked in the biobattery.
\end{abstract}

Keywords: magnetic nanoparticles; bioelectrode; biofuel cell; enzyme; fructose dehydrogenase; laccase

\section{Introduction}

Currently, the use of natural resources, in particular fossil fuels, is higher than our planet can regenerate. In connection with the above, it is important to develop renewable energy sources, which include biofuel cells. In classical fuel cells, noble metals, such as platinum and nickel, are used as catalysts. Enzymatic biofuel cells are a special type of fuel cell that uses enzymes from living cells as catalysts [1-4]. They have several advantages: enzymes are relatively easy to obtain in mass production. Moreover, they also have special properties that enable them to convert various organic compounds (sugars, alcohols) that are used as fuels in biofuel cells. Due to the fact that sugars and other biofuels can be grown and harvested on a massive scale, the fuel for enzymatic biofuel cells is cheap and can be found almost everywhere. Enzymes are also common in nature. Most organic compounds cannot be used as fuel in fuel cells with noble metal catalysts because carbon monoxide (II) which is formed during the work of the fuel cell, quickly "poisons" the surface of the metal and hampers its further use.

The most commonly used enzymes which are used to construct the bioelectrodes in a biofuel cell include glucose oxidase, fructose dehydrogenase, glucose dehydrogenase, laccase, bilirubin oxidase, and cellobiose dehydrogenase [2,5]. In biofuel cells, the enzymes are most often immobilized on the electrodes' surface (anodes and cathodes), and their 
performance is effective. If the enzymes are not immobilized on the electrodes, they disperse in the fuel, and most of the released electrons do not reach the electrodes. This behavior obviously worsens the effectiveness of the biofuel cell. Even if the enzymes are properly immobilized on the electrode, the appropriate conditions for electron transfer from and to the electrode should be provided. The electron transfer from the enzyme to the electrode surface and from the electrode surface to the enzyme can take place either directly (direct electron transfer) [6,7] or by mediators (mediated electron transfer) $[2,6]$, which facilitate the transfer of electrons from the enzyme to the electrode or from the electrode to the enzyme. This first method of the electron transport is only possible in some types of enzymes, in which the active sites are close to the enzyme surface. However, in most cases, the active center of the enzyme is deeply located in the protein structure and is electrically isolated with a thick layer of organic matter. To overcome the kinetic barrier in the electron transport in the bioelectrocatalytic system, active redox compounds (i.e., mediators) can be introduced. The mediators are usually very helpful in achieving electrical communication between the enzyme and the electrode surface, but the increased complexity of the system due to the introduction of additional components can cause further problems in the work of the biofuel cell.

Biofuel cells can be prospectively used in living organisms [4,8]; hence it is important to develop biofuel cells that are based on direct electron transport. The application of additional compounds, such as mediators, may also complicate the work operation of the cell and can be toxic to the living organisms. Therefore, very often, the enzymes and mediators are immobilized on the electrode surface. There is a huge variety of strategies for immobilizing both enzymes and mediators, which include simple physical adsorption, covalent attachment, crosslinking, and entrapment in polymer gels. A combination of different methods for the immobilization of enzymes or mediators is often used. It is also important to use different modifiers, as for example, carbon nanotubes, carbon particles, gold nanoparticles, and other materials, on the electrode surface to immobilize enzymes or mediators. Basically, these systems are used to increase the active surface area of the electrode. These structures can also provide a suitable substrate for immobilizing the enzymes while maintaining their activity for a long time. Even when good electrical communication is achieved between the enzyme and the electrode surface, fuel transport may also be a major problem.

In our previous studies, we used various nanomaterials to immobilize enzymes on the electrode surface, i.e., gold nanoparticles, carbon nanoparticles, fullerenes, carbon nanotubes, and porous carbon as well [9-13]. Magnetic nanoparticles are one of the materials that have been recently studied. Nowicka et al. showed that carbon-encapsulated iron nanoparticles (CEINs) are an appropriate substrate for the immobilization of laccase [14]. The presence of laccase on the electrode surface caused a significant shift in the position of the oxygen reduction signal towards positive potentials. The use of an external magnetic field substantially increased the catalytic current of oxygen reduction. Matysiak et al. [15] modified the electrode surface using CEINs and demonstrated that the application of an external permanent magnet results in a very efficient voltammetric sensor for testing the concentration of ceruloplasmin in real biological samples, including blood. The developed ceruloplasmin sensor was able to detect both ceruloplasmin protein and other paramagnetic molecules, such as hemoglobin and transferrin, in the same blood sample during one measurement. In a similar way, the hemoglobin sensor has been developed, in which the symbiosis of CEINs and an external magnetic field was presented [16]. Barrio and coworkers [17] used $\mathrm{Fe}_{3} \mathrm{O}_{4}$ magnetic nanoparticles combined with glucose oxidase, fluorescein, and a ruthenium derivative for continuous monitoring of glucose. They used sensors as intelligent diagnostic tattoos. Kizling and coworkers [18] presented that magnetic interactions between the paramagnetic heme centers of fructose dehydrogenase and superparamagnetic iron oxide nanoparticles allow the proper orientation of the enzyme molecule and increase the rate of direct electron transfer. The large proximity of the FDH heme to the electrode decreased the fructose oxidation overpotential as well as diminished 
the Michaelis-Menten constant and generally improved the electrode performance in the presence of an external magnetic field.

In this work, carbon-encapsulated iron nanoparticles were used to immobilize enzymes: fructose dehydrogenase and laccase on the electrode. Electrochemically modified electrodes were characterized in the absence of a mediator in the case of laccase and 1,4-naphthoquinone mediator using fructose dehydrogenase. D-fructose dehydrogenase is a protein found in the cell membrane [19]. A characteristic feature of FDH is its strong direct electron transfer (DET) bioelectrocatalytic activity [20-23]. Laccase belongs to blue oxidases and participates in the crosslinking of monomers, polymer degradation, and cleavage of aromatic rings. It is widespread in higher plants and mushrooms. In recent years, these enzymes have found application in the textile, cellulose, and paper industries, as well as the food industry. Laccase is also used in the development of biosensors and fuel cells. These systems use the property of laccase to reduce oxygen to water $[5,13,24]$. In addition, this enzyme is used in medical diagnostics and as a bioremediation agent for the removal of petroleum substances, removal of herbicides and pesticides from soil and groundwater. Over the past few decades, laccase has gained the interest of researchers due to its ability to oxidize both phenolic and non-phenolic lignin-related compounds, as well as highly resistant environmental pollutants [24]. In this work, the tested biocathode with laccase was used to construct the biofuel cell, and the full characteristics were presented in a three-electrode system. The unprecedented in the literature and described in this work is the use of a bioanode as well as biocathode with CEINs as the electrode substrate for the immobilization of enzymes. The biofuel cell uses the biocathode with CEINs and laccase, while bioanode includes CEINs and fructose dehydrogenase.

\section{Results and Discussion}

\subsection{Electrode Modified with CEINs and Laccase}

The reduction of oxygen proceeds with a large overpotential at the unmodified glassy carbon electrode (GCE) at potentials ca. $-0.6 \mathrm{~V}$ vs. $\mathrm{Ag} / \mathrm{AgCl}$ reference electrode both in the absence and presence of laccase. Laccase is used in the presence of dissolved or immobilized mediators on the electrode to reduce the overpotential of oxygen reduction. In addition, catalytic reduction of oxygen at positive potentials can be observed using laccase and various nanostructures, e.g., carbon nanotubes or gold nanoparticles, as described in previous articles [9-13].

The modified glassy carbon electrode covered with carbon-encapsulated iron nanoparticles and laccase was used in this study. The cyclic voltammetric curves were recorded in the potential range between $0.8 \mathrm{~V}$ to $0.2 \mathrm{~V}$ with the scan rate of $0.001 \mathrm{~V} / \mathrm{s}$ in the deoxygenated and oxygenated Mcllvaine buffer $\mathrm{pH} 6.0$ (Figure 1). In the absence of oxygen, no signals were observed on the recorded voltammetric curves. A catalytic wave was observed in the oxygenated buffer, which started at the potential of about $0.54 \mathrm{~V}$. This wave corresponded to the catalytic reduction of oxygen by laccase. Next, the current density values were determined and were as follow: $-35.64 \mu \mathrm{W} / \mathrm{cm}^{2}$ and $-7.50 \mu \mathrm{W} / \mathrm{cm}^{2}$ for the oxygenated and deoxygenated buffer, respectively. The current values were measured from the voltammetric curves at $0.2 \mathrm{~V}$. Due to the use of Nafion in the laccase immobilization procedure, the electrodes were stable, and the decrease in the catalytic reduction current over time was not observed. The above findings show that carbon-encapsulated iron nanoparticles are a suitable material for the immobilization of laccase in the mediator-free laccase catalyzed reduction of oxygen. The potential at which the catalytic process on the electrode begins is positive enough, hence this electrode can be used as the biocathode in the construction of biobattery, biofuel cell, or oxygen sensor. 


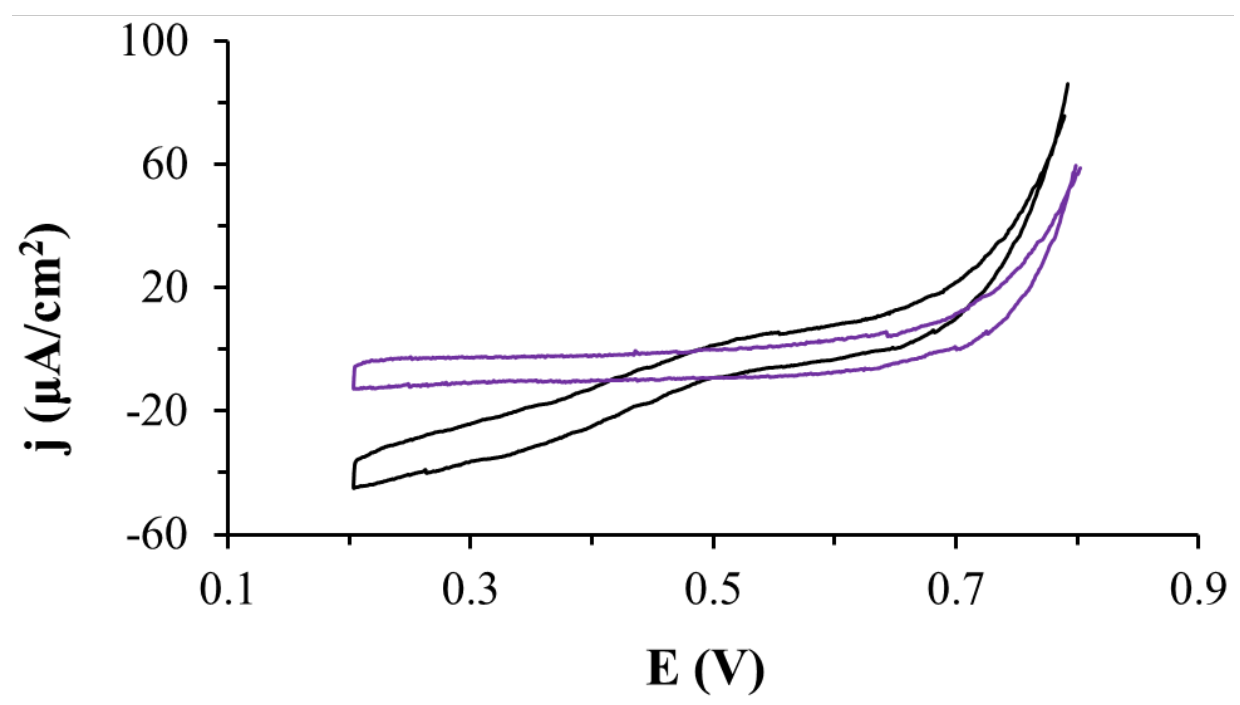

Figure 1. Cyclic voltammetric curves recorded on GCE modified with CEINs and laccase in Nafion layer recorded in deoxygenated (blue curve) and oxygenated (black curve) McIlvaine buffer $\mathrm{pH}$ 6.0, scan rate $0.001 \mathrm{~V} / \mathrm{s}$.

\subsection{Electrode Modified with CEINs and Fructose Dehydrogenase}

The glassy carbon disc electrode covered with carbon-encapsulated iron nanoparticles and fructose dehydrogenase was used in the study. In this case, 1,4-naphthoquinone was used as the mediator of the electron transport. The use of a naphthoquinone derivative as the mediator has been previously reported to be advantageous for the enzyme since it leads to a decrease in the overpotential of the catalytic reaction [22,25-27]. First, the suspensions of CEINs were dropped on the electrode surface. Next, 1,4-naphtoquinone was electrochemically adsorbed. In the final step, fructose dehydrogenase was adsorbed, and Nafion was added. 1,4-naphthoquinone was adsorbed on a glassy carbon disc electrode covered with CEINs by cycling the modified electrode in the Mcllvaine buffer containing $1 \mathrm{mM}$ 1,4-naphthoquinone.

The cycling was carried out in the potential range between $0.4 \mathrm{~V}$ and $-0.4 \mathrm{~V}$ with a scan rate of $0.1 \mathrm{~V} / \mathrm{s}$ (Figure 2). The first cycle on the voltammetric curve showed redox signals: the reduction peak at $-0.24 \mathrm{~V}$ and the oxidation peak at $-0.03 \mathrm{~V}$. These features resulted from the redox process of 1,4-naphthoquinone. The oxidation and reduction peaks increased with each number of the voltammetric cycles. Moreover, the reduction peak potential shifted to more negative potentials, and the oxidation peak also moved to the more positive range. These observations indicate that 1,4-naphthoquinone was successfully adsorbed on the modified electrode surface. Most likely, the cycling in a solution containing 1,4-naphthoquinone resulted in a formation of a polymer on the modified electrode. Analogous observations have been described in the literature for similar compounds [28,29]. After adsorption of the mediator, the voltammetric curves were recorded in the potential range between $-0.4 \mathrm{~V}$ and $0.2 \mathrm{~V}$ in the deoxygenated Mcllvaine buffer $\mathrm{pH} 6.0$ without 1,4-naphthoquinone at various potential scan rates (Figure 3A). The oxidation and reduction current densities increased with an increase in the scan rate. The linear dependence of the current density of the anode and cathode peaks on the scan rate of potential confirms the surface nature of the redox process and proves the successful adsorption of 1,4-naphthoquinone on the glassy carbon electrode modified with carbon-encapsulated iron nanoparticles (Figure 3B). The oxidation and reduction peaks were located at $-0.01 \mathrm{~V}$ and $-0.20 \mathrm{~V}$ on the cyclic voltammetry curve recorded at scan rate $0.1 \mathrm{~V} / \mathrm{s}$. The difference between the cathode and anode peak was slightly smaller as compared to the adsorption process of 1,4 naphthoquinone, which proves that the system has higher conductivity. 


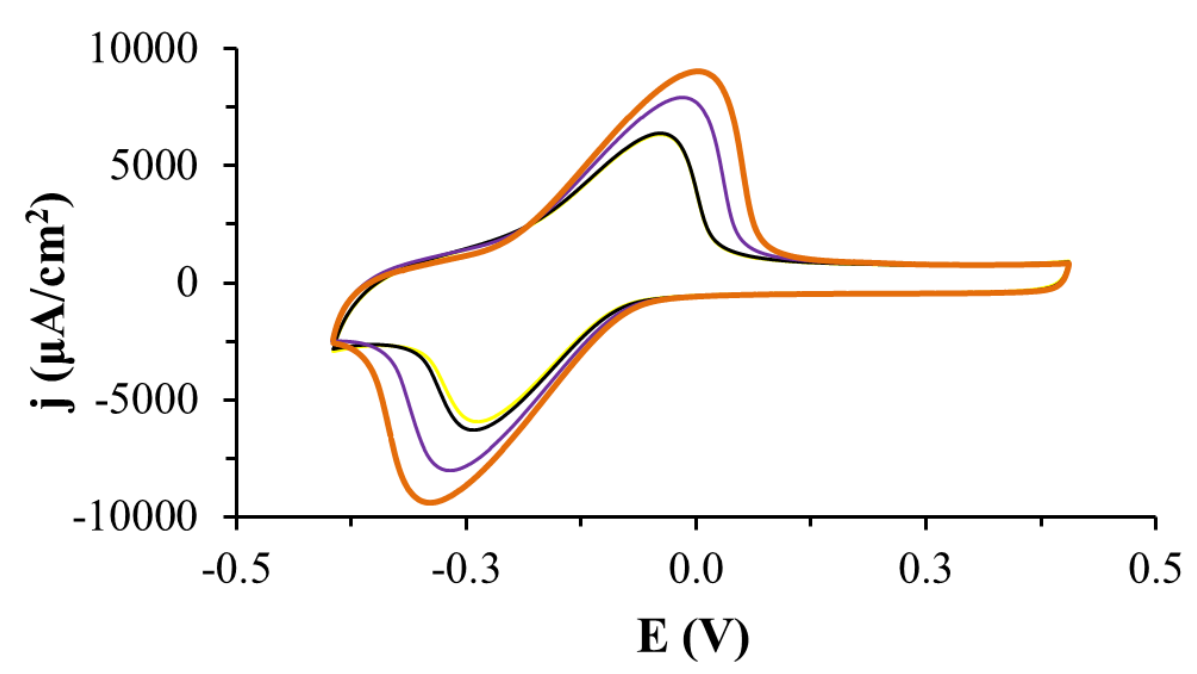

Figure 2. Cyclic voltammetric curves recorded on GCE electrode modified with CEINs in deoxygenated McIlvaine buffer $\mathrm{pH} 6.0$ containing $1 \mathrm{mM}$ 1,4-naphthoquinone, 1 (yellow curve), 2 (black curve), 10 (blue curve), 20 cycles (orange curve), scan rate $0.1 \mathrm{~V} / \mathrm{s}$.

(A)

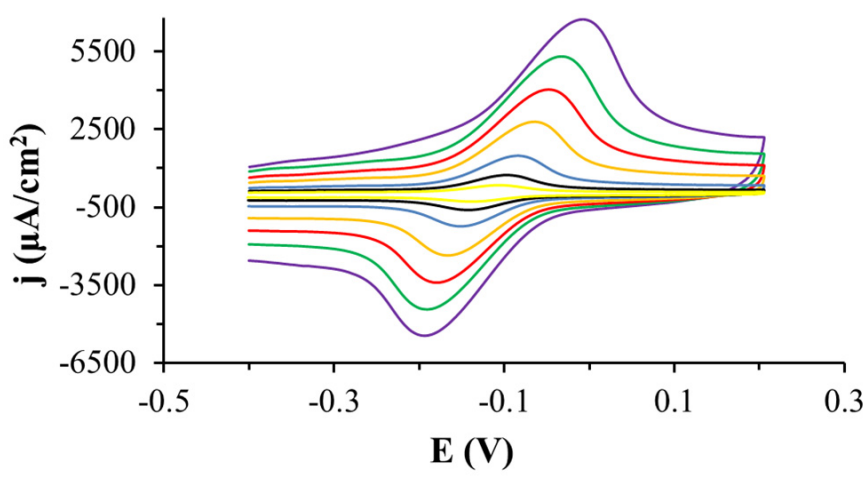

(B)

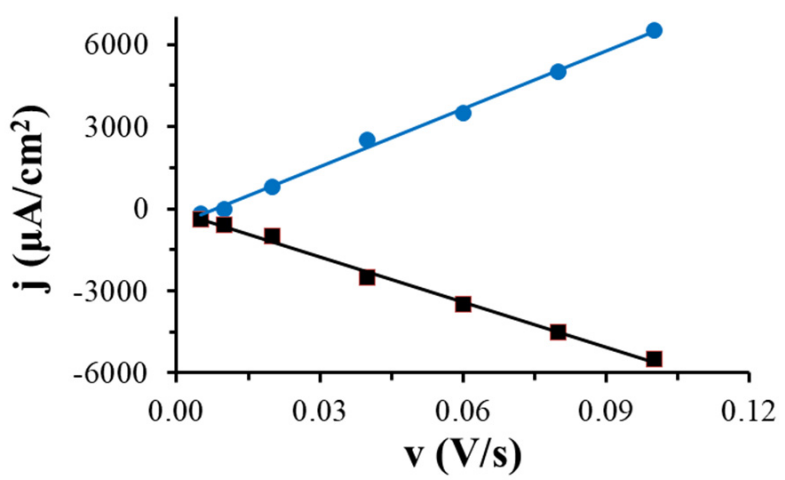

Figure 3. (A) Cyclic voltammetric curves recorded on GCE electrode modified with CEINs in deoxygenated McIlvaine buffer pH 6.0, scan rate 0.005 (yellow curve), 0.01 (black curve), 0.02 (blue curve), 0.04 (orange curve), 0.06 (red curve), 0.08 (green curve), 0.1 (violet curve) V/s. (B) Dependence of current density vs. scan rate: black squares and line (reduction peak), blue dots and line (oxidation peak).

In the next step, a fructose dehydrogenase solution was dropped on the modified electrode and left in the fridge overnight to adsorb the enzyme. Then, Nafion was added onto the electrode to protect the electrode from leaching the enzyme out. The voltammetric curves (Figure 4A) were recorded in the deoxygenated Mcllvaine buffer without and with fructose in the potential between -0.4 and $0.4 \mathrm{~V}$. In the absence of fructose in solution, the redox signals originating from 1,4-naphthoquinone adsorbed on the electrode were observed on the voltammetric curves: the oxidation peak at $-0.11 \mathrm{~V}$ and the reduction peak at $-0.15 \mathrm{~V}$. Then the voltammetric curves were recorded in deoxygenated solutions containing fructose at different concentrations. The catalytic waves were observed, and the current density started to increase at the potential of $-0.19 \mathrm{~V}$. This was a signal from the catalytic oxidation of fructose by fructose dehydrogenase in the presence of 1,4-naphthoquinone. The catalytic current density increased with an increase in the fructose concentration (Figure 4A). The dependence of the catalytic current density determined at $0.4 \mathrm{~V}$ vs. fructose concentration is shown in Figure 4B. A linear relationship between current density and fructose concentration was observed in the fructose concentration range between 0 and $50 \mathrm{mM}$. At higher concentrations, the curve tended to have a plateau. 
This is likely related to the amount of fructose dehydrogenase, which is not large enough to process all the fructose present in the solution.

(A)

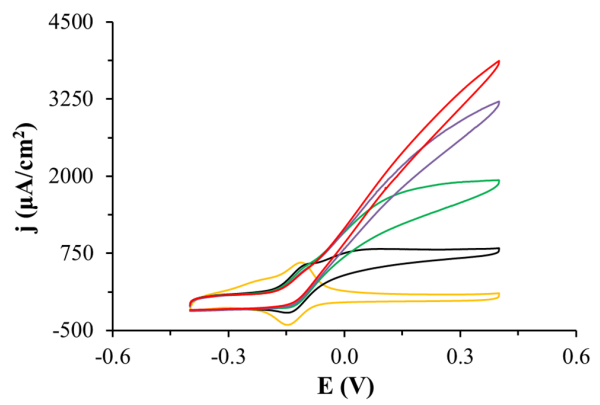

(B)

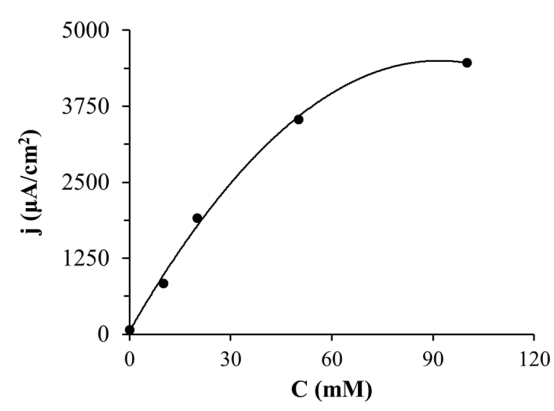

Figure 4. (A) Cyclic voltammetric curves recorded on GCE modified with CEINs, 1,4-naphthoquinone, fructose dehydrogenase and Nafion in deoxygenated McIlvaine buffer $\mathrm{pH} 6.0$ containing 0 (yellow curve), 10 (black curve), 20 (green curve), 50 (blue curve), 100 (red curve) mM fructose, scan rate $0.005 \mathrm{~V} / \mathrm{s}$. (B) Catalytic current density at $0.4 \mathrm{~V}$ vs. fructose concentration.

To summarize, it was demonstrated that both 1,4-naphthoquinone (the mediator of the electron transport) and fructose dehydrogenase were successfully introduced on the glassy carbon electrode modified with carbon-encapsulated iron nanoparticles. The developed electrode was stable, and no leaching of 1,4-naphthoquinone and fructose dehydrogenase from the electrode surface was observed. The potential at which catalytic oxidation of fructose occurred is very attractive for the construction of a fructose sensor or as a bioanode in a biofuel cell.

\subsection{Biobattery Studies}

Biobattery tests were carried out in a three-electrode system consisting of the anode, which was a zinc plate (A: $\mathrm{Zn}$ ), the cathode made of a modified glassy carbon disc electrode with CEINs, laccase, and Nafion (C: CEINs Lc Nf), and the reference electrode was a silver/silver chloride electrode $(\mathrm{Ag} / \mathrm{AgCl})$. The current parameters of the biobattery were determined from experiments carried out using a specially constructed system comprising the multimeter and the resistor. The measurements were performed using a special computer program to acquire the data. A gradually decreasing resistance from 10,000 $\mathrm{k} \Omega$ to $1 \mathrm{k} \Omega$ was mounted in the biobattery between the cathode and the anode, as well between the cathode and the reference electrode, and the anode and the reference electrode. Then the voltage between the cathode and anode, the cathode and the reference electrode, and the reference electrode and the anode was monitored [30]. The tests were carried out in the oxygenated and deoxygenated McIlvaine buffer $\mathrm{pH}$ 6.0. Figure 5 shows the dependence of the power density vs. the current density and the current density vs. the potential difference between the reference electrode and anode as well as the cathode. An increase in the power density with increasing the current density was observed in both buffers, i.e., oxygenated and deoxygenated solutions (Figure 5A). The biobattery current values obtained from the measurements are presented in Table 1 . The biobattery with the cathode made of modified glassy carbon electrode (under aerobic conditions) generated a maximum power of $7148 \mu \mathrm{W} / \mathrm{cm}^{2}$, which corresponded to the current density of 10,055 $\mu \mathrm{A} / \mathrm{cm}^{2}$ and the voltage of $0.71 \mathrm{~V}$ at the resistance of $1 \mathrm{k} \Omega$. The open-circuit voltage $(\mathrm{OCV})$ for this system was $1.51 \mathrm{~V}$. At anaerobic conditions, this biobattery generated a maximum power of $525 \mu \mathrm{W} / \mathrm{cm}^{2}$, which corresponded to the current density of $2725 \mu \mathrm{A} / \mathrm{cm}^{2}$ and the voltage of $0.19 \mathrm{~V}$ at the resistance of $1 \mathrm{k} \Omega$, and the open-circuit voltage $(\mathrm{OCV})$ was $0.55 \mathrm{~V}$. However, for the oxygenated buffer the determined power density values were much higher in comparison to the deoxygenated solution due to the lack of fuel which is oxygen for the biocathode. 
(A)

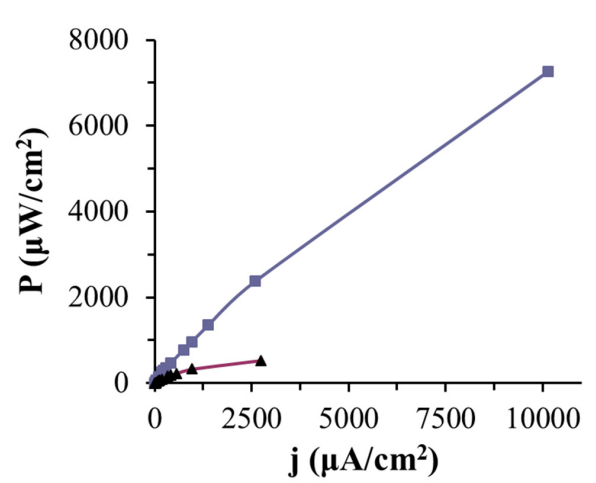

(B)

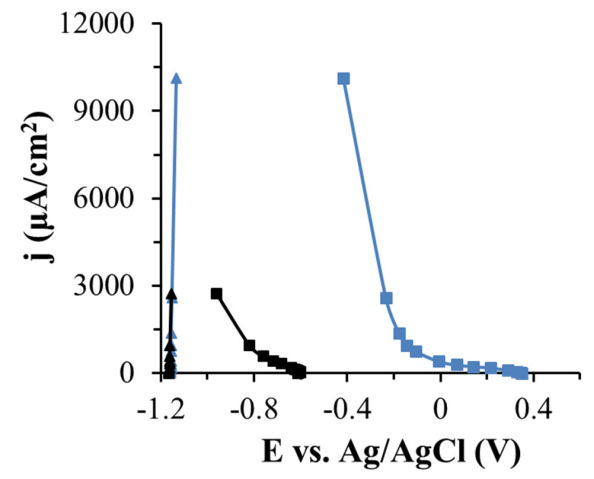

Figure 5. (A) Biobattery power density vs. current density A: Zn C: CEINs Lc Nf, (B) Current density of anode $(\boldsymbol{\Lambda}, \mathbf{\Lambda})$ and cathode $(\boldsymbol{\square}, \mathbf{\square})$ vs. potential of reference electrode; deoxygenated (black curve, black mark) and oxygenated (blue curve, blue mark) McIlvaine buffer $\mathrm{pH} 6.0$.

Table 1. Parameters of biobattery A: Zn C: CEINs Lc Nf measured in oxygenated and deoxygenated Mcllvaine buffer $\mathrm{pH}$ 6.0 and biofuel cells anode A: CEINs NQ FDH Nf C: CEINs Lc Nf in oxygenated/with fructose and deoxygenated/without fructose in Mcllvaine buffer $\mathrm{pH}$ 6.0.

\begin{tabular}{ccccc}
\hline \multirow{2}{*}{ Cell } & \multicolumn{2}{c}{ Biobattery } & \multicolumn{2}{c}{ Biofuel Cell } \\
\cline { 2 - 5 } Electrolyte & $\begin{array}{c}\text { A: Zn C: CEINs Lc Nf } \\
\text { buffer } \mathrm{pH} 6.0\end{array}$ & $\begin{array}{c}\text { A: CEINs NQ FDH Nf C: CEINs Lc Nf } \\
\text { Mcllvaine buffer } \mathrm{pH} \text { 6.0 }\end{array}$ & $\begin{array}{c}\text { oxygenated McIlvaine buffer } \\
\mathrm{pH} \text { 6.0, } 100 \text { mM fructose }\end{array}$ & $\begin{array}{c}\text { deoxygenated McIlvaine } \\
\text { buffer pH } 6.0,0 \text { mM fructose }\end{array}$ \\
\hline $\mathrm{P}\left(\mu \mathrm{W} / \mathrm{cm}^{2}\right)$ & $7147.60 \pm 160.68$ & $524.97 \pm 8.09$ & $78.37 \pm 3.83$ & $0.96 \pm 0.13$ \\
\hline $\mathrm{j}\left(\mu \mathrm{W} / \mathrm{cm}^{2}\right)$ & $10,054.46 \pm 113.02$ & $2724.90 \pm 21.01$ & $235.40 \pm 5.75$ & $26.06 \pm 1.75$ \\
\hline $\mathrm{E}(\mathrm{V})$ & $0.71 \pm 0.01$ & $0.19 \pm 0.01$ & $0.33 \pm 0.01$ & $0.04 \pm 0.01$ \\
\hline $\mathrm{R}(\mathrm{k} \Omega)$ & 1 & 1 & 20 & 20 \\
\hline $\mathrm{OCV}(\mathrm{V})$ & $1.51 \pm 0.01$ & $0.55 \pm 0.01$ & $0.49 \pm 0.03$ & $0.05 \pm 0.01$ \\
\hline
\end{tabular}

Figure 5B shows the dependence of the current density vs. the potential difference between the reference electrode and the anode and the cathode. It is evident that the potential of the zinc electrode (black and blue curves, triangular markers) during the measurement in both deoxygenated and oxygenated solutions remained almost unchanged (about $-1.1 \mathrm{~V}$ ). In the case of biocathode, together with the reduction in the resistance, the biocathode potential decreased, and this phenomenon was observed in both oxygenated and deoxygenated solutions. The zinc electrode played the role of reference electrode for the cathode because the shape of the power density curve from the current density in a two-electrode biobattery system depends only on the properties of the biocathode. In the case of a biobattery, the biocathode half-cell was a system that determined the operational capabilities of the biobattery.

\subsection{Biofuel Cell Studies}

Biofuel cell experiments were carried out in a three-electrode system consisting of the anode, which was a modified glassy carbon disc electrode modified with CEINs, 1,4-naphthoquinone, fructose dehydrogenase, and Nafion (A: CEINs NQ FDH Nf), the cathode, which was a modified glassy carbon disc electrode with CEINs, laccase, and Nafion (C: CEINs Lc Nf), and the reference electrode was a silver/silver chloride electrode $(\mathrm{Ag} / \mathrm{AgCl})$. The biofuel cell measurements were performed in the same way as for the biobattery tests. A gradually decreasing resistance from $10,000 \mathrm{k} \Omega$ to $1 \mathrm{k} \Omega$ was mounted in the biobattery between the cathode and the anode, as well between the cathode and the reference electrode, and the anode and the reference electrode. Then the voltage between 
the cathode and anode, the cathode and reference electrode, and the reference electrode and anode was monitored. Figure 6 shows the dependence of the power density vs. the current density and the current density vs. the potential difference between the reference electrode, the anode, as well as the cathode. The power density increased with the increase in current density (Figure 6A) both in the oxygenated solution of fructose and the deoxygenated solution without fructose. Importantly, for the case of the oxygenated buffer, the power density was much higher as compared to the deoxygenated solution without fructose. For the lower resistance range applied, both the power density and current density increased. For the oxygenated solution with fructose on the recorded curves, a maximum power density equal to $78.37 \mu \mathrm{W} / \mathrm{cm}^{2}$ appeared at $0.33 \mathrm{~V}$, and then power density decreased to zero with a further reduction in resistance. The characteristics of the biofuel cell obtained from the measurements are presented in Table 1. The biofuel cell generated a maximum power of $78.37 \mu \mathrm{W} / \mathrm{cm}^{2}$, which corresponded to the current density of $235.40 \mu \mathrm{A} / \mathrm{cm}^{2}$ and the voltage of $0.33 \mathrm{~V}$ at $20 \mathrm{k} \Omega$ resistance. The open-circuit voltage (OCV) for this system was $0.49 \mathrm{~V}$. However, in anaerobic conditions and the absence of fructose in solution, the biofuel cell generated a maximum power of $0.96 \mu \mathrm{W} / \mathrm{cm}^{2}$, which corresponded to the current density of $26.06 \mu \mathrm{A} / \mathrm{cm}^{2}$ and the voltage of $0.04 \mathrm{~V}$ at $20 \mathrm{k} \Omega$ resistance, and the open-circuit voltage (OCV) was $0.05 \mathrm{~V}$.

(A)

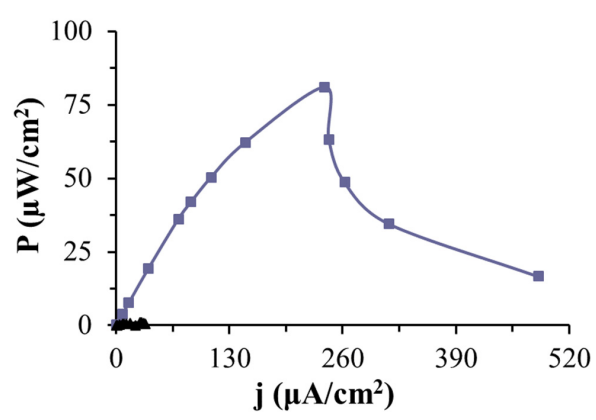

(B)

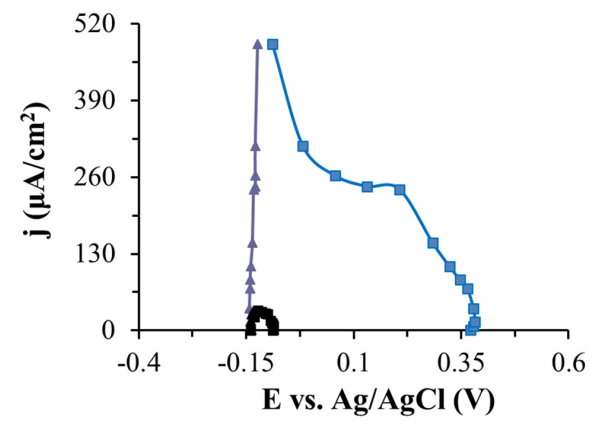

Figure 6. (A) Biofuel cell power density vs. current density A: CEINs NQ FDH Nf C: CEINs Lc Nf. (B) Current density of anode $(\boldsymbol{\Lambda}, \mathbf{\Delta})$ and cathode $(\boldsymbol{\square}, \mathbf{\square})$ vs. potential of the reference electrode, electrolyte: $100 \mathrm{mM}$ fructose/oxygenated (blue curve, blue marker). $0 \mathrm{mM}$ fructose/deoxygenated (black curve, black marker) Mcllvaine buffer $\mathrm{pH}$ 6.0.

Oxygen is the reactant for the laccase-catalyzed reaction, and fructose is the reactant of the FDH-catalyzed reaction, respectively. This information explains the following observation. For the oxygenated solution in the presence of fructose, an increase in maximum power (82 times) and current density (9 times) was observed in comparison to the deoxygenated solutions and in the absence of fructose. Based on Figure 6B, it can be concluded that the change in the biofuel cell current parameters resulted from the changes in the potential response of both the cathode and the anode. The dependence of the current density of the anode vs. potential of the reference electrode recorded in the oxygenated buffer containing fructose was a straight line, which suggests it worked more efficiently than the biocathode. Such behavior was expected since the mediator was used in the presence of an enzyme, and it facilitated the transport of electrons between the enzyme and the electrode surface. The obtained maximum cell power is comparable, or even greater, in comparison with the data presented by Kizling et al. [12] for porous carbon electrodes modified with gold nanoparticles and FDH and laccase, where the maximum cell power density of $41.3 \mu \mathrm{W} / \mathrm{cm}^{2}$ was obtained. Much lower power density and current density values were achieved in the biofuel cell compared to the biobattery. These limitations are due to the lower open-circuit voltage, which was an effect of more positive bioanode potential in the biofuel cell as compared to the zinc anode. This is due to the low efficiency of the biocathode (the catalytic reduction of oxygen in the presence of laccase loaded on carbon-encapsulated iron nanoparticles), which was manifested in a very rapid decrease in 
the potential with a simultaneous decrease in the resistance (Figure 6B). The essence of this publication was to show that both fructose dehydrogenase and laccase are active in the presence of carbon-encapsulated iron nanoparticles.

\section{Materials and Methods}

\subsection{Materials and Chemicals}

Carbon encapsulated iron nanoparticles (CEINs) were synthesized using a carbon arc discharge method described elsewhere [31]. The carbon arc was ignited between the graphite cathode and the anode which was composed of iron (70 wt.\%) and graphite (30 wt.\%). The discharge was conducted under a hydrogen-argon atmosphere (60 kPa, 1:1). The as-obtained material was purified with $3 \mathrm{M} \mathrm{HCl}$ for $5 \mathrm{~h}$ at boiling point with subsequent rinsing with distilled water. The purification was needed to remove the non-encapsulated iron nanoparticles. The obtained CEINs had a diameter between 10 and $100 \mathrm{~nm}$ (determined via TEM inspection). CEINs had typical weak ferromagnetic characteristics with the saturation magnetization of $70 \mathrm{emu} / \mathrm{g}$. They rapidly reacted to external magnets. Powder X-ray diffraction pattern and TEM images of carbon-encapsulated iron nanoparticles are shown in Figures S1 and S2, respectively (see Supplementary Material).

The Cerrena unicolor C-139 laccase lyophilized samples in vials were obtained from Prof. Jerzy Rogalski, the Department of Biochemistry, Maria Curie-Sklodowska University in Lublin Poland [32]. The activity of laccase stock solution after dissolving the protein powder from vial in $1 \mathrm{~mL}$ of Milli-Q water was equal to $128 \mathrm{U}$ per mg of protein. Fructose dehydrogenase with activity $145 \mathrm{U} / \mathrm{mg}$ was obtained from Sorachim (Lausanne, Switzerland). The inorganic and organic reagents of the highest purity were commercially available from Avantor (Gliwice, Poland) and Sigma-Aldrich (Saint Louis, MO, USA). They were used without purification. Argon and oxygen (99.5\%) were used from Air Products (Kielce, Poland). Nanopure water (resistance $18.2 \mathrm{M} \Omega / \mathrm{cm}$ ) was obtained from the Milli-Q purification system (Millipore Corporation, Bedford, MA, USA).

\subsection{Electrochemical Instrumentation and Procedures}

The Mcllvaine buffer $\mathrm{pH} 6.0$ was prepared by mixing appropriate proportions of aqueous solutions of $0.2 \mathrm{M} \mathrm{Na}_{2} \mathrm{HPO}_{4}$ with $0.1 \mathrm{M}$ citric acid.

A solution of $1 \%$ Nafion in ethanol was prepared by adding $0.2 \mathrm{~mL}$ of $5 \%$ Nafion to $0.8 \mathrm{~mL}$ ethanol solution. A $0.5 \%$ aqueous Nafion solution was prepared by adding $0.1 \mathrm{~mL}$ $5 \%$ Nafion to $0.9 \mathrm{~mL}$ distilled water.

A suspension of carbon-encapsulated iron nanoparticles (CEINs) in ethanol was prepared by adding $25 \mathrm{mg}$ of CEINs to $1 \mathrm{~mL}$ of ethanol. The mixture was then left for $20 \mathrm{~min}$ in an ultrasonic bath to obtain a homogeneous suspension.

Fructose dehydrogenase solution was prepared by adding $10 \mathrm{mg}$ of fructose dehydrogenase to $100 \mu \mathrm{L}$ of Mcllvaine buffer $\mathrm{pH}$ 6.0.

The laccase solution was prepared by adding $1 \mathrm{~mL}$ Mcllvaine buffer $\mathrm{pH} 6.0$ to one vial of laccase.

The laccase solution with Nafion was prepared by mixing $50 \mu \mathrm{L}$ Mcllvaine buffer pH 6.0 and $50 \mu \mathrm{L} \mathrm{1 \%} \mathrm{Nafion} \mathrm{solution.}$

Before surface modification, the glassy carbon electrode was cleaned. This process was based on the physical removal of surface impurities by polishing the electrode on a polishing cloth with the addition of an aqueous suspension of alumina with a grain size of about 0.05 micrometers. In the next step, the electrode surface was washed with distilled water to remove residual alumina particles and washed with ethanol. Finally, the electrode was wiped with Kimberly-Clark dust-free wipes.

The electrode with CEINs and laccase was prepared by applying a $10 \mu \mathrm{L}$ suspension of CEINs to a clean, glassy carbon disc electrode and allowed to dry in air. Next, $10 \mu \mathrm{L}$ of a mixture of laccase and Nafion was dropped onto the carbon electrode modified with magnetic nanoparticles and allowed to dry in air. 
The carbon electrode modified with CEINs and fructose dehydrogenase was prepared by applying a $10 \mu \mathrm{L}$ suspension of CEINs to a cleaned glassy carbon electrode. After drying the electrode, 1,4-naphthoquinone was electrochemically adsorbed onto it. 1,4-naphthoquinone was adsorbed on a carbon disc electrode covered with CEINs by cycling the modified electrode in the Mcllvaine buffer containing $1 \mathrm{mM}$ 1,4-naphthoquinone. The cycling was carried out in the potential range between $0.4 \mathrm{~V}$ and $-0.4 \mathrm{~V}$ with a scan rate of $0.1 \mathrm{~V} / \mathrm{s}$. After cleaning the electrode by water and drying, $10 \mu \mathrm{L}$ fructose dehydrogenase solution was added and left overnight in the fridge for physical adsorption of FDH on the electrode surface. Finally, $10 \mu \mathrm{L}$ of a $0.5 \%$ aqueous Nafion solution was added and allowed to dry in air.

Voltammetric measurements were made using a PGSTAT20 Eco Chemie Autolab potentiostat (Utrecht, The Netherlands). The measurements were made in a three-electrode system, where the working electrode was a glassy carbon disc electrode (BASi ${ }^{\circledR}$, Kent Avenue, IN, USA) with $0.071 \mathrm{~cm}^{2}$ electrode surface area, the reference electrode was the silver/silver chloride electrode filled with the saturated solution of potassium chloride $\left(\mathrm{Ag} / \mathrm{AgCl}, \mathrm{KCl}_{\text {sat }}\right)$, and the counter electrode was the platinum electrode $(\mathrm{Pt})$ in the form of a platinum plate. The experiments were carried out in a special electrochemical vessel containing Mcllvaine buffer $\mathrm{pH}$ 6.0. Mcllvaine buffer during measurements ensured constant ion activity and was the basic electrolyte as well. The electrolyte solutions were either deoxygenated or oxygenated by bubbling either argon or oxygen through these solutions for $20 \mathrm{~min}$. During the measurements, gas was passed through the solution. The measured currents were converted into current densities. The obtained current values were divided by the geometric surface of the working electrode.

The biobattery experiments were carried out in a three-electrode system which consisted of an anode zinc plate (Goodfellow, Huntingdon, UK) coated with a hopeite layer. The layer was formed during zinc electrode oxidation Mcllvaine buffer. A glassy carbon disc was served as the cathode, while the reference electrode was the same as in the voltammetric measurements. The biofuel cell experiments were carried out in a similar system as for the biobattery. The anode was made of a modified glassy carbon disc electrode. The surface area of the anode was the same as the surface area of the cathode. The experiments were performed in Mcllvaine buffer $\mathrm{pH}$ 6.0, which was oxygenated or deoxygenated. During the measurements, gas was passed through the solution. The parameters of the cell were determined from experiments and carried out using a specially constructed system consisting of the M3500A Multimeter (Picotest, Phoenix, AZ, USA) and a homemade resistor. The measurements were controlled using a PC computer. In the system, a gradually decreasing resistance from $10,000 \mathrm{k} \Omega$ to $1 \mathrm{k} \Omega$ was applied between the cathode and the anode within $5 \mathrm{~s}$. Then, the voltage between the cathode and anode, the cathode and reference electrode, and the reference electrode and anode were recorded. From the obtained results, the current density was calculated using the Ohm's law equation, and the cell power or density power was calculated from the power formula $(\mathrm{P}=\mathrm{U} \times \mathrm{I})$. The dependence $P(j), E$ (j) showed the efficiency of a biobattery and biofuel cell in the range of applied resistances. All experiments were carried out in $22 \pm 2{ }^{\circ} \mathrm{C}$ temperature.

\section{Conclusions}

This work demonstrated the application of carbon-encapsulated iron nanoparticles in the development of bioelectrodes in a biobattery and biofuel cell. The study studied two enzymes: fructose dehydrogenase and laccase. Carbon-encapsulated iron nanoparticles were shown to be a suitable material for the immobilization of laccase because the mediator-free catalytic reduction of oxygen in the presence of laccase was achieved. The very low overpotential potential of the catalytic process allowed us the use the electrode as the biocathode in the biobattery and the biofuel cell. Carbon-encapsulated iron nanoparticles are a suitable material for the immobilization of 1,4-naphthoquinone and fructose dehydrogenase. The system was stable; no leaching of 1,4-naphthoquinone or fructose dehydrogenase from the surface of the modified electrode was observed. The potential 
at which catalytic oxidation of fructose took place was positive; therefore, the modified electrode could be used for the construction as a bioanode in the biofuel cell.

The biobattery with the zinc plate anode, the cathode modified with carbon encapsulated iron nanoparticles, laccase in the Nafion layer showed advantageous parameters: maximum power of $7148 \mu \mathrm{W} / \mathrm{cm}^{2}$ at $0.71 \mathrm{~V}$ and under the resistance of $1 \mathrm{k} \Omega$, and opencircuit voltage as high as $1.51 \mathrm{~V}$. The new biofuel cell consisted of the anode: glassy carbon electrode coated with carbon encapsulated iron nanoparticles, 1,4-naphthoquinone, fructose dehydrogenase, and Nafion, and cathode modified with carbon encapsulated iron nanoparticles, laccase in Nafion layer. A maximum power of $78 \mu \mathrm{W} / \mathrm{cm}^{2}$ was obtained at $0.33 \mathrm{~V}$ and under a resistance of $20 \mathrm{k} \Omega$. The open-circuit voltage of the biofuel cell for this system was $0.49 \mathrm{~V}$. Carbon-encapsulated iron nanoparticles were used as the supportive electrode substrate for the immobilization of fructose dehydrogenase and laccase. These enzymes worked effectively in the biofuel cell, while laccase effectively worked in the biobattery as well.

Supplementary Materials: The following are available online at https:/ /www.mdpi.com/article/10 $.3390 /$ catal11060705/s1, Figure S1: Powder X-ray diffraction pattern of carbon-encapsulated iron nanoparticles, Figure S2: TEM images of carbon-encapsulated iron nanoparticles.

Author Contributions: K.S.: idea, structure, and design of the paper; planning for the work related to the publication; analyzed the data; wrote this manuscript. K.S. is the supervisor of the master thesis of R.C. R.C. performed the experiments under the supervision of K.S. M.B. delivered carbonencapsulated iron nanoparticles and participated in manuscript preparation. All authors have read and agreed to the published version of the manuscript.

Funding: This project was supported by grant MINIATURA 1-competition for single scientific activities, project No. 2017/01/X/ST4/01166 from the National Science Centre, Poland.

Conflicts of Interest: The authors declare no conflict of interests.

\section{References}

1. Falk, M.; Blum, Z.; Shleev, S. Direct electron transfer based enzymatic fuel cells. Electrochim. Acta 2012, 82, 191-202. [CrossRef]

2. Luz, R.A.S.; Pereira, A.R.; de Souza, J.C.P.; Sales, F.C.P.F.; Crespilho, F.N. Enzyme Biofuel Cells: Thermodynamics, Kinetics and Challenges in Applicability. ChemElectroChem 2014, 1, 1751-1777. [CrossRef]

3. Santoro, C.; Arbizzani, C.; Erable, B.; Ieropoulos, I. Microbial fuel cells: From fundamentals to applications. A review. J. Power Sources 2017, 356, 225-244. [CrossRef]

4. Zebda, A.; Alcaraz, J.-P.P.; Vadgama, P.; Shleev, S.; Minteer, S.D.; Boucher, F.; Cinquin, P.; Martin, D.K. Challenges for successful implantation of biofuel cells. Bioelectrochemistry 2018, 124, 57-72. [CrossRef]

5. Kamitaka, Y.; Tsujimura, S.; Setoyama, N.; Kajino, T.; Kano, K. Fructose/dioxygen biofuel cell based on direct electron transfer-type bioelectrocatalysis. Phys. Chem. Chem. Phys. 2007, 9, 1793-1801. [CrossRef]

6. Ivanov, I.; Vidaković-Koch, T.; Sundmacher, K. Recent advances in enzymatic fuel cells: Experiments and modeling. Energies 2010, 3, 803. [CrossRef]

7. Yan, X.; Tang, J.; Tanner, D.; Ulstrup, J.; Xiao, X. Direct electrochemical enzyme electron transfer on electrodes modified by self-assembled molecular monolayers. Catalysts 2020, 10, 1458. [CrossRef]

8. Zhou, M. Recent Progress on the Development of Biofuel Cells for Self-Powered Electrochemical Biosensing and Logic Biosensing: A Review. Electroanalysis 2015, 27, 1786-1810. [CrossRef]

9. Zelechowska, K.; Stolarczyk, K.; Łyp, D.; Rogalski, J.; Roberts, K.P.; Bilewicz, R.; Biernat, J.F. Aryl and N-arylamide carbon nanotubes for electrical coupling of laccase to electrodes in biofuel cells and biobatteries. Biocybern. Biomed. Eng. 2013, 33, 235-245. [CrossRef]

10. Majdecka, D.; Draminska, S.; Stolarczyk, K.; Kizling, M.; Krysinski, P.; Golimowski, J.; Biernat, J.F.; Bilewicz, R. Sandwich biobattery with enzymatic cathode and Zinc anode integrated with sensor. J. Electrochem. Soc. 2015, 162. [CrossRef]

11. Kizling, M.; Biedul, P.; Zabost, D.; Stolarczyk, K.; Bilewicz, R. Application of Hydroxyethyl Methacrylate and Ethylene Glycol Methacrylate Phosphate Copolymer as Hydrogel Electrolyte in Enzymatic Fuel Cell. Electroanalysis 2016, 28. [CrossRef]

12. Kizling, M.; Dzwonek, M.; Olszewski, B.; Baccal, P.; Tymecki, Ł.; Więckowska, A.; Stolarczyk, K.; Bilewicz, R. Reticulated vitreous carbon as a scaffold for enzymatic fuel cell designing. Biosens. Bioelectron. 2017, 95, 1-7. [CrossRef]

13. Olszewski, B.; Stolarczyk, K. Laccase-catalyzed reduction of oxygen at electrodes modified by carbon nanotubes with adsorbed promazine or acetosyringone. Catalysts 2018, 8, 414. [CrossRef] 
14. Nowicka, A.M.; Kowalczyk, A.; Donten, M.L.; Donten, M.; Bystrzejewski, M.; Stojek, Z. Carbon-encapsulated iron nanoparticles as ferromagnetic matrix for oxygen reduction in absence and presence of immobilized laccase. Electrochim. Acta 2014, 126, 115-121. [CrossRef]

15. Matysiak, E.; Wagner, B.; Bystrzejewski, M.; Grudzinski, I.P.; Nowicka, A.M. Direct voltammetric detection of ceruloplasmin in blood in presence of other paramagnetic species. Sens. Actuators B Chem. 2015, 221. [CrossRef]

16. Matysiak, E.; Donten, M.; Kowalczyk, A.; Bystrzejewski, M.; Grudzinski, I.P.; Nowicka, A.M. A novel type of electrochemical sensor based on ferromagnetic carbon-encapsulated iron nanoparticles for direct determination of hemoglobin in blood samples. Biosens. Bioelectron. 2015, 64, 554-559. [CrossRef] [PubMed]

17. del Barrio, M.; Moros, M.; Puertas, S.; de la Fuente, J.M.; Grazú, V.; Cebolla, V.; de Marcos, S.; Galbán, J. Glucose oxidase immobilized on magnetic nanoparticles: Nanobiosensors for fluorescent glucose monitoring. Microchim. Acta 2017, 184, 1325-1333. [CrossRef]

18. Kizling, M.; Rekorajska, A.; Krysinski, P.; Bilewicz, R. Magnetic-field-induced orientation of fructose dehydrogenase on iron oxide nanoparticles for enhanced direct electron transfer. Electrochem. Commun. 2018, 93, 66-70. [CrossRef]

19. Wettstein, C.; Kano, K.; Schäfer, D.; Wollenberger, U.; Lisdat, F. Interaction of Flavin-Dependent Fructose Dehydrogenase with Cytochrome $\mathrm{c}$ as Basis for the Construction of Biomacromolecular Architectures on Electrodes. Anal. Chem. 2016, 88, 6382-6389. [CrossRef]

20. Tominaga, M.; Shirakihara, C.; Taniguchi, I. Direct heterogeneous electron transfer reactions and molecular orientation of fructose dehydrogenase adsorbed onto pyrolytic graphite electrodes. J. Electroanal. Chem. 2007, 610, 1-8. [CrossRef]

21. Kawai, S.; Yakushi, T.; Matsushita, K.; Kitazumi, Y.; Shirai, O.; Kano, K. Electrochemistry Communications The electron transfer pathway in direct electrochemical communication of fructose dehydrogenase with electrodes. Electrochem. Commun. 2014, 38, 28-31. [CrossRef]

22. Kizling, M.; Bilewicz, R. Fructose Dehydrogenase Electron Transfer Pathway in Bioelectrocatalytic Reactions. ChemElectroChem 2018, 5, 166-174. [CrossRef]

23. Adachi, T.; Kaida, Y.; Kitazumi, Y.; Shirai, O.; Kano, K. Bioelectrocatalytic performance of D-fructose dehydrogenase. Bioelectrochemistry 2019, 129, 1-9. [CrossRef] [PubMed]

24. Shekher, R.; Sehgal, S.; Kamthania, M.; Kumar, A. Laccase: Microbial sources, production, purification, and potential biotechnological applications. Enzyme Res. 2011, 2011. [CrossRef]

25. Giroud, F.; Milton, R.D.; Tan, B.-X.; Minteer, S. Simplifying Enzymatic Biofuel Cells: Immobilized Naphthoquinone as a Biocathodic Orientational Moiety and Bioanodic Electron Mediator. ACS Catal. 2015, 5, 1240-1244. [CrossRef]

26. Milton, R.D.; Hickey, D.P.; Abdellaoui, S.; Lim, K.; Wu, F.; Tan, B.; Minteer, S.D. Rational design of quinones for high power density biofuel cells. Chem. Sci. 2015, 6, 4867-4875. [CrossRef]

27. Hou, C.; Lang, Q.; Liu, A. Electrochimica Acta Tailoring 1, 4-naphthoquinone with electron-withdrawing group: Toward developing redox polymer and FAD-GDH based hydrogel bioanode for ef fi cient electrocatalytic glucose oxidation. Electrochim. Acta 2016, 211, 663-670. [CrossRef]

28. Kobayashi, S.; Higashimura, H. Oxidative polymerization of phenols revisited. Prog. Polym. Sci. 2003, 28, 1015-1048. [CrossRef]

29. Bao, L.; Xiong, R.; Wei, G. Electrochemical polymerization of phenol on 304 stainless steel anodes and subsequent coating structure analysis. Electrochim. Acta 2010, 55, 4030-4038. [CrossRef]

30. Stolarczyk, K.; Kizling, M.; Majdecka, D.; Zelechowska, K.; Biernat, J.F.; Rogalski, J.; Bilewicz, R. Biobatteries and biofuel cells with biphenylated carbon nanotubes. J. Power Sources 2014, 249, 263-269. [CrossRef]

31. Bystrzejewski, M.; Łabedź, O.; Kaszuwara, W.; Huczko, A.; Lange, H. Controlling the diameter and magnetic properties of carbon-encapsulated iron nanoparticles produced by carbon arc discharge. Powder Technol. 2013, 246, 7-15. [CrossRef]

32. Rola, B.; Karaśkiewicz, M.; Majdecka, D.; Mazur, I.; Bilewicz, R.; Rogalski, J.; Ohga, S. Scale up of cerrena unicolor lacease production. J. Fac. Agric. Kyushu Univ. 2013, 58, 231-238. [CrossRef] 